\title{
Longitudinal study of free running exercise challenge: reproducibility
}

\author{
C V E Powell, R D White, R A Primhak
}

\begin{abstract}
The reproducibility of free running exercise challenge has been examined in an unselected population of 8-10 year olds. Using a standardised protocol, monthly exercise tests were performed on 143 children over one year. A positive test was defined using both a 15\% and $20 \%$ fall in peak expiratory flow after exercise. The mean ( $95 \%$ confidence interval, CI) population frequency for a positive test at $15 \%$ fall was $14.9 \%(6.5$ to $23 \cdot 3)$ and coefficient of variation $24 \cdot 6 \%$. For a $20 \%$ fall, the mean $(95 \% \mathrm{CI})$ population frequency was $7.9 \%(2.9$ to 12.9$)$ and coefficient of variation $27 \cdot 8 \%$. Seventy two $(50 \cdot 3 \%)$ of the children gave at least one positive response at $15 \%$ fall. Exercise testing is not reproducible in the community setting and should not be used as a screening test. Exercise data from epidemiological studies of asthma should be interpreted with caution.

(Arch Dis Child 1996; 74: 108-114)
\end{abstract}

Keywords: exercise testing, asthma, screening, reproducibility.

Exercise challenge has been used in the epidemiological study of wheezy illness in children to support subjective questionnaire data with an objective measure of airway dysfunction. ${ }^{1-3}$ In the search for a screening tool for undiagnosed asthma it has also been suggested that children are screened regularly with free running tests to identify children with possible undiagnosed asthma. ${ }^{45}$

The exercise test in the laboratory has been standardised and is reproducible over short periods of time. ${ }^{6-8}$ Haby et al have suggested a standardised exercise protocol for epidemiological studies of asthma in children. ${ }^{9}$ There are no longitudinal data on the performance of free running tests in a community population. If a test is to be used for screening then one of the most important characteristics of the test is that it should be reproducible. ${ }^{10}$ The reproducibility in an unselected community based population of children has not been assessed nor has the relationship between response to exercise and respiratory symptoms.

The aim of this study was to assess longitudinally the free running exercise test in an unselected community based sample. We have examined the reproducibility of the test and the within-individual variability of the response in a population of 8-10 year old children.

\section{Methods}

Two local junior schools agreed to participate in the study. A cross sectional sample of children aged between 8 and 10 years were enrolled. Their parents were asked to complete a screening questionnaire to assess current respiratory morbidity ${ }^{11}$ and a consent form at the beginning of the study year.

Free running exercise tests were completed on a monthly basis from July 1992-June 1993. Similar methodology for every free running test was used and they were completed by the same two workers throughout the study. Before each test, standing height was measured using a portable Rollameter (Raven) and evidence of a current upper respiratory tract infection (URTI) was sought by history and clinical examination.

\section{LUNG FUNCTION TESTING}

Peak expiratory flow (PEF) measurements were used as a measure of lung function. Each child made three attempts at a PEF manoeuvre and the best of the three attempts was recorded as the pre-exercise flow rate. Lung function measurements were taken with the child standing and without a nose clip. If their PEF was below $60 \%$ of the predicted value they were not asked to run. The predicted values for PEF were calculated from accepted standards. ${ }^{12}$ The PEF measurements were taken by one experienced worker throughout the length of the study and were taken blind to previous results and responses.

There were two Wright peak flow meters used throughout the study and instrument variability was examined by measuring the PEF of four healthy workers before and after the studies. ${ }^{3}$

On the first occasion of testing the children were trained to perform a satisfactory PEF manoeuvre and the flow rates were not recorded until the effort and method was considered to be optimal. Each subsequent test started with instructions for the peak flow rate manoeuvre throughout the study to reinforce the method.

\section{EXERCISE TESTING}

Cohorts of five children were asked to run around a flat, wooden floored gymnasium for six minutes. If a child was known to have asthma they were instructed to take their asthma medication as they would normally do before exercise. All the children were encouraged to run as hard as possible. Any child deemed to be making inadequate effort throughout the six minutes was asked to stop 
Table 1 The numbers of children examined at each exercise test illustrating those children who were absent or refused to run. Included are 11 children who left the school over the year and nine children who joined the school during the year

\begin{tabular}{llllllll}
\hline Tests & $\begin{array}{l}\text { Noof } \\
\text { children }\end{array}$ & Absent & $\begin{array}{l}\text { Didn't } \\
\text { run }\end{array}$ & $\begin{array}{l}\text { Total } \\
\text { possible }\end{array}$ & $\begin{array}{l}\text { Left } \\
\text { school }\end{array}$ & $\begin{array}{l}\text { Not at } \\
\text { school yet }\end{array}$ & $\begin{array}{l}\text { Grand } \\
\text { total }\end{array}$ \\
\hline 1 & 105 & 28 & 1 & 134 & 0 & 9 & 143 \\
2 & 123 & 16 & 0 & 139 & 0 & 4 & 143 \\
3 & 116 & 18 & 1 & 135 & 4 & 4 & 143 \\
4 & 122 & 17 & 1 & 137 & 2 & 4 & 143 \\
5 & 125 & 8 & 1 & 134 & 7 & 2 & 143 \\
6 & 117 & 15 & 0 & 132 & 9 & 2 & 143 \\
7 & 99 & 31 & 3 & 133 & 9 & 1 & 143 \\
8 & 116 & 15 & 2 & 133 & 9 & 1 & 143 \\
9 & 116 & 14 & 3 & 133 & 10 & 0 & 143 \\
10 & 116 & 11 & 5 & 132 & 11 & 0 & \\
\hline
\end{tabular}

running and the data obtained from that single test was not used.

Once a child had completed six minutes of running they were asked to stop and rest with no further activity until the final PEF was obtained. Heart rates were randomly checked in $20 \%$ of the children at the end of the test to ensure they had reached submaximal levels (170 beats per minute). The distance run by each child was not measured nor did they use nose clips during running.

The best of three attempts at PEF was then measured at five, 10, and 15 minutes after exercise as described above. Every child had to stop and rest after exercise until all lung function tests were completed. As the testing went on throughout the day, those children who were tested in the afternoon were kept in the classroom and not allowed to have their breaks outside to avoid exercising before the tests.

If a child developed bronchospasm severe enough to cause respiratory symptoms the child was given an inhaled bronchodilator. This was done under the supervision of a doctor and with the consent of the parent which had been obtained at the beginning of the study.

\section{CONDITIONS OF THE TESTING}

The tests took place in the same room throughout the study period and the doors and windows were kept shut on each occasion to reduce any ventilation effects. Throughout the study an attempt was made to study each child at the same time of day for each test. Ambient temperature and absolute humidity were recorded by a portable monitor (Rotronics, London) throughout each day to ensure the absolute water content remained below $10 \mathrm{mg}$ $\mathrm{H}_{2} \mathrm{O} /$.

\section{ANALYSIS}

Data were analysed using a Statsview 512+ package. The per cent predicted PEF before exercise was calculated as above. The per cent falls in PEF at five, 10, and 15 minutes after exercise were calculated for each subject using the formula:

Before exercise PEF-after exercise PEF Before exercise PEF

The maximum percentage fall during the first 15 minutes after exercise was used for analysis (fall index). Children with no history of reported wheeze in the last 12 months and no history of asthma or atopy ${ }^{13} 14$ were used as a normative population. The cut off point for a 'normal' percentage fall after exercise in our population was taken as the mean plus 1.96 SD of the percentage fall in the normative population. We have also examined a cut off point of a $15 \%$ drop after exercise as this has been used by many workers. ${ }^{2-4} 15$

The within-population variability of a positive test was assessed. The frequency of a positive response was calculated for each test. The mean, $95 \%$ confidence interval $(\mathrm{CI})$, and the coefficient of variation for the frequency of a positive response were then calculated. The within-individual variability was also examined by calculating the cumulative frequency of a positive test within the population and the percentage of positive tests elicited in each child.

\section{Results}

\section{POPULATION}

(A) Schools

The two schools were tested on different days but testing occurred at both schools within two weeks of each other each month. Testing started in July 1992. August was missed because of the school holidays and testing continued monthly until June 1993. The tests were attempted once a month but for practical reasons in October we could only visit school B and in December we could only visit school A. Thus there were 10 possible tests in all for each child.

\section{(B) The children}

A total of 143 children were assessed of which $80(55.6 \%)$ were boys. The modal age of the children was 9 years, but ranging from 8-10 years. The mean (SD) for height at the beginning of the study was $138.0(7 \cdot 7) \mathrm{cm}$ for the boys and $138.9(9.4) \mathrm{cm}$ for the girls.

During the study period 11 children left the schools and nine children joined the schools. There were a total of 76 children attending school $\mathrm{A}$ and 67 attending school B. There were a number of children either absent on the day of study, unable to run due to injury, or excluded because of inadequate effort. Thus not all 143 children were tested 10 times. Details of the numbers actually tested each time, children present but unable to run, and those who were absent are given in table 1 .

Table 2 The individual frequency of exercise testing for 143 children aged 8-10 years; 10 possible tests to complete

\begin{tabular}{lllll}
\hline Tests & $\begin{array}{l}\text { No of } \\
\text { children }\end{array}$ & Cumulative & $\begin{array}{l}\% \\
\text { Population }\end{array}$ & $\begin{array}{l}\text { Cumulative \% } \\
\text { population }\end{array}$ \\
\hline 10 & 45 & 45 & $32 \cdot 0$ & $32 \cdot 0$ \\
9 & 34 & 79 & $23 \cdot 0$ & $55 \cdot 0$ \\
8 & 25 & 104 & $17 \cdot 5$ & $72 \cdot 5$ \\
7 & 15 & 119 & $10 \cdot 0$ & $83 \cdot 0$ \\
6 & 3 & 122 & $2 \cdot 0$ & $85 \cdot 0$ \\
5 & 5 & 127 & $3 \cdot 5$ & $88 \cdot 5$ \\
4 & 5 & 132 & $3 \cdot 5$ & $92 \cdot 0$ \\
3 & 7 & 139 & $5 \cdot 0$ & $97 \cdot 0$ \\
2 & 3 & 142 & $2 \cdot 5$ & $99 \cdot 5$ \\
1 & 1 & 143 & 0.5 & $100 \cdot 0$ \\
\hline
\end{tabular}


Table 3 Respiratory symptoms reported in 118 out of 143 children who completed the exercise testing. The normative group $(n=82)$ and the other children in the cohort $(n=36)$ are presented separately along with the total; figures are number (\% of that group)

\begin{tabular}{lclr}
\hline & Total & 'Normal' & 'Others' \\
\hline Symptom & & & \\
$\quad$ Ever wheezed & $31(26 \cdot 3)$ & $6(7 \cdot 4)$ & $25(67 \cdot 6)$ \\
$\quad$ Current asthma & $11(9 \cdot 3)$ & 0 & $11(29 \cdot 7)$ \\
$\quad$ Wheezed in last 12 months & $22(18 \cdot 6)$ & 0 & $22(59 \cdot 5)$ \\
In the last 12 months & $6(5 \cdot 1)$ & 0 & $6(16 \cdot 2)$ \\
$\quad$ More than four attacks of wheeze & $7(5 \cdot 9)$ & 0 & $7(18 \cdot 9)$ \\
Sleep disturbed at least once a week & $4(3 \cdot 4)$ & 0 & $4(10 \cdot 8)$ \\
Wheeze preventing speech & $16(13 \cdot 6)$ & $8(9 \cdot 9)$ & $8(21 \cdot 6)$ \\
Night cough at least once a week & $14(11 \cdot 9)$ & $5(6 \cdot 2)$ & $9(16 \cdot 2)$ \\
Exercise limited by cough or wheeze most times & & &
\end{tabular}

'Normal' are children with no current wheeze, no diagnosis of asthma, and no atopy as per text.

\section{FREQUENCY OF TESTING}

There were $45(32 \%)$ children who were tested 10 times and $119(83 \%)$ children were tested at least seven times. The remaining $24(17 \%)$ children had between one and six tests. Table 2 illustrates the frequency of testing.

\section{QUESTIONNAIRES}

There were 118 returned respiratory questionnaires $(82 \cdot 5 \%)$. The exercise test characteristics of those 25 children who did not reply to the questionnaire were analysed within the main study group. The prevalence of respiratory symptoms reported are illustrated in table 3. Of those 11 children who were currently diagnosed as having asthma, seven were reported to be taking inhaled prophylaxis and four were reported to be taking intermittent $\beta_{2}$ agonists as sole treatment. The respiratory symptoms recorded in the 45 children who completed all the 10 exercise tests were similar to those in the complete cohort.

\section{TEST RESULTS}

The absolute water content remained below 10 $\mathrm{mg} \mathrm{H}_{2} \mathrm{O} / \mathrm{l}$ (using the ambient temperature and absolute humidity recordings) during every test. Of those children who had their pulse rate assessed immediately at the end of each test, $95 \%$ had achieved heart rates above 170 beats per minute. The median (range) point prevalence of an URTI for the tests was $6.8 \%$ $(1 \cdot 6-11 \cdot 7)$. PEF before exercise (per cent predicted) throughout the year are displayed in fig 1. This includes all children with asthma and

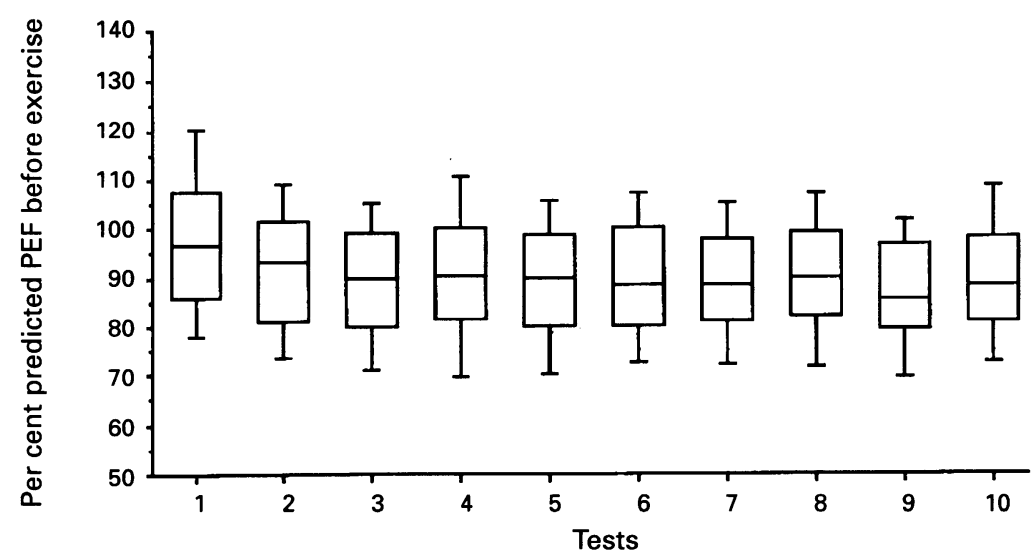

Figure 1 Box and whisker plots of per cent predicted PEF before exercise for all 10 tests. Median and quartiles are shown in boxes and 90th centiles by whiskers. current upper respiratory tract infections as well as symptom free children. Box and whisker plots for maximum drop in PEF at any time in the 15 minutes after exercise are illustrated in fig 2 .

There were $82(56.6 \%)$ children who met the criteria for a normal population. Their respiratory symptoms reported on questionnaire are illustrated in table 3. The mean (SD) for the maximum drop in PEF after exercise in these children over the year was $5 \cdot 2(7 \cdot 6)$. The cut off point for an abnormal per cent fall in this study was thus $20 \cdot 1 \%$. Thirteen children within this population reported nocturnal or exercise related cough as isolated symptoms. If they were excluded from the analysis the cut off point was unchanged $(20 \cdot 06 \%)$.

WITHIN-POPULATION VARIABILITY

We examined the frequency of a positive test for all 10 tests. The mean (SD) of a positive response was then calculated for the two different cut off points.

\section{$15 \%$ Fall index}

The mean (SD) frequency of a positive test using a $15 \%$ fall index was $14.9 \%(3 \cdot 7)$. The range was $9 \cdot 4 \%$ to $20.0 \%$ ( $95 \%$ CI 6.5 to $23 \cdot 3$ ) and the coefficient of variation for the test was $24 \cdot 6 \%$. The mean (SD) for the 45 children who completed all 10 tests was $17 \%(6 \cdot 1)$ with a range of $12.6 \%$ to $21.4 \%$ (95\% CI 3.0 to $30 \cdot 8$ ). The coefficient of variation was $36 \cdot 0 \%$.

\section{$20 \%$ Fall index}

Using a $20 \%$ fall index the mean (SD) frequency of a positive test was $7.9 \%(2 \cdot 2)$. The range was $4 \cdot 3 \%$ to $10 \cdot 4 \%$ (95\% CI $2 \cdot 9$ to $12 \cdot 9)$ and the coefficient of variation was $27 \cdot 8 \%$. For the 45 children who completed all 10 tests, the mean (SD) frequency of a positive test was $9 \cdot 3 \%(3 \cdot 3)$. The range was 4.4 to $13.3(95 \%$ CI 1.9 to $16 \cdot 7)$ and the coefficient of variation was $35 \cdot 5 \%$.

In order to examine the possible relationship between an URTI and the high coefficient of variation seen in the frequency of a positive test, all children with an URTI were excluded from the next analysis.

For a $15 \%$ fall index, the mean (SD) frequency of a positive text, excluding those with current URTI, was $14.3 \%(3.5)$ with range between $9.9 \%$ to $17.9 \%$ and coefficient of variation $24 \cdot 1 \%$. For a cut off point of $20 \%$ fall index, the mean (SD) frequency of a positive test, excluding those with current URTI, was $7 \cdot 3 \%(2 \cdot 3)$ with range between $3 \cdot 2 \%$ to $9 \cdot 4 \%$ and coefficient of variation $32 \cdot 0 \%$.

\section{WITHIN-INDIVIDUAL VARIATION}

The cumulative frequency of a positive response was examined. There were $72(50 \cdot 3 \%)$ of the study population who gave at least one positive response at a $15 \%$ cut off point and $40(27 \cdot 9 \%)$ who gave at least one positive response using the $20 \%$ cut off point. The cumulative frequency of 


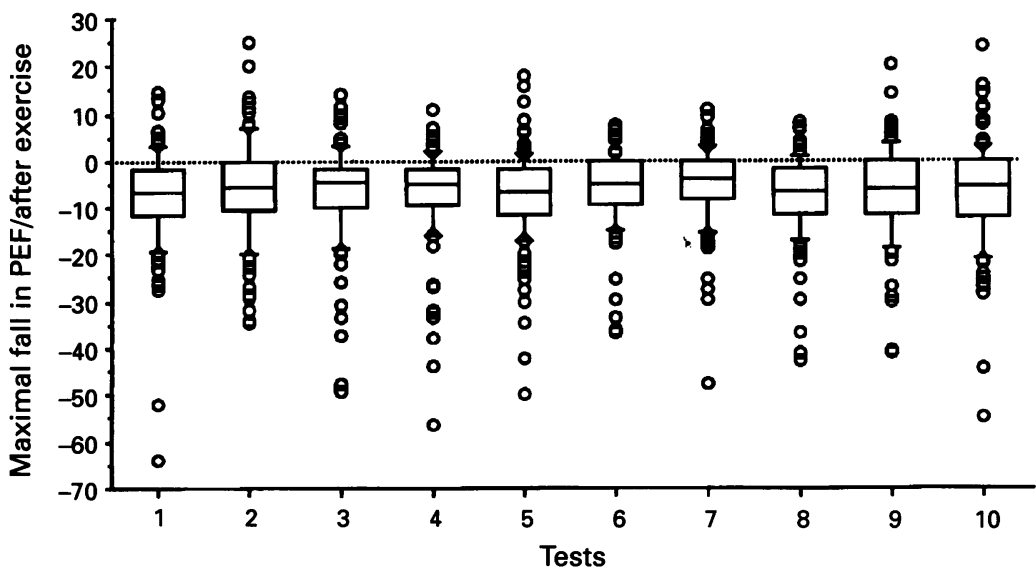

Figure 2 Box and whisker plots of maximal fall in PEF after exercise for all 10 tests. Median and quartiles are shown in boxes, 90th centiles by whiskers, and outliers as individual points. test if the underlying condition is itself variable; we would suggest that if a screening test is to be of value it should be able to identify a condition even when quiescent. Lack of reproducibility has been cited as a major potential flaw in a screening procedure. ${ }^{10}$

Some workers have repeated one exercise test some years apart to explore the changing prevalence of asthma in children ${ }^{15}$ and others have used exercise tests along with questionnaires to draw epidemiological conclusions about asthma. ${ }^{2}$ In view of the wide confidence limits of population estimates of bronchial hyperreactivity (BHR) that we have demonstrated, such comparisons and conclusions drawn from cross sectional studies using one exercise test only should be viewed with caution.

The return rate of $82.5 \%$ from the initial questionnaire was comparable with other prevalence studies. ${ }^{1617}$ The respiratory morbidity reported in this questionnaire was similar to the larger contemporaneous study on 8-10 year old children in Sheffield reported previously. ${ }^{18} \mathrm{We}$ therefore feel we have examined a representative population of children.

The questions used are part of a standardised validated questionnaire for respiratory epidemiology in children. ${ }^{11}$ This contains questions of satisfactory reproducibility over short periods of time which has also been tested on Sheffield children (unpublished data). We therefore feel that we have used a currently acceptable questionnaire. There are still reservations regarding the data obtained from questionnaires in this setting but until there is a definite test to diagnose asthma in community studies this is probably the best tool we have available at the moment. ${ }^{19}$

Exercise testing in the laboratory has been well standardised and has been shown to have of free running exercise test in a community based population of primary schoolchildren. We have demonstrated that under field conditions the results obtained within an individual are not reproducible and that the suggestion that exercise testing should be used as a screening test for undiagnosed asthma cannot be supported. ${ }^{4} 5$ It could be argued that this variation in results does not invalidate a screening

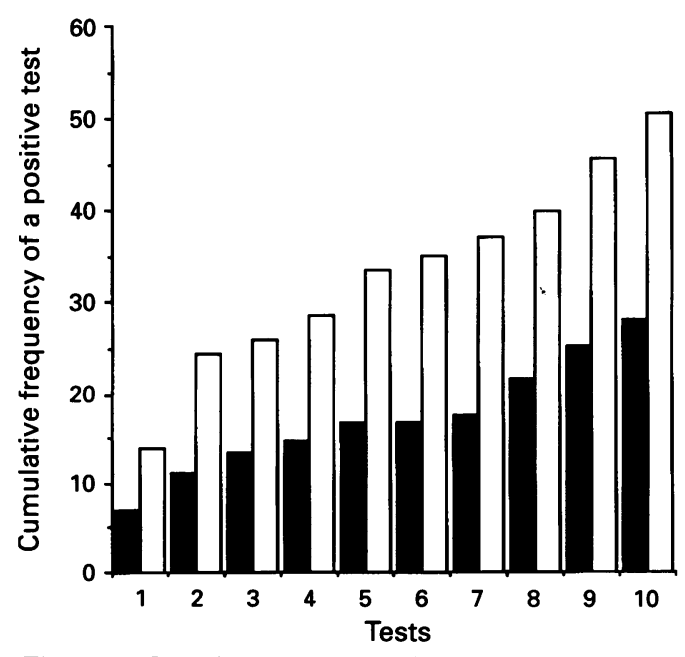

Figure 3 Cumulative percentage frequency of a positive test at both a $20 \%$ fall index (total number $=40$ ) and $a$ $15 \%$ fall index (total number $=72$ ).
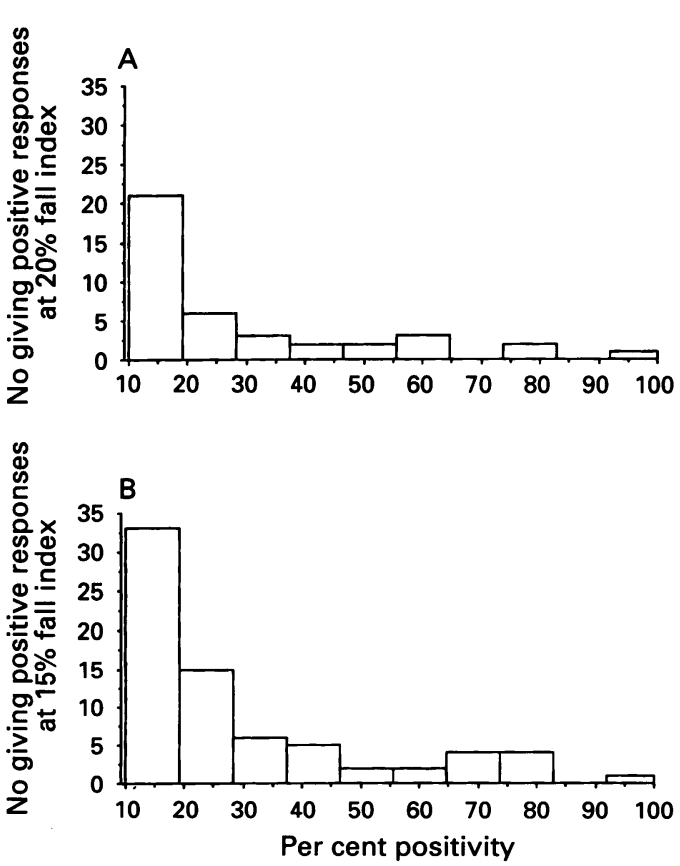

Figure 4 Number of children who gave a positive response at $(A) 20 \%$ and $(B) 15 \%$ fall index. Per cent positivity is the proportion of times a child gave a positive result compared with the number of times the child was studied (calculated as a per cent). 
good reproducibility over short periods. ${ }^{6-8}$ The children examined in these studies have been 'normal' children with absolutely no symptoms at all or children with definite asthma selected from a hospital population. Haby et al have suggested a standardised exercise protocol for epidemiological studies of asthma on unselected populations. ${ }^{9}$ They emphasised that the reproducibility of the test is as yet unclear and needs to be assessed in the field.

There may be a number of reasons why we have demonstrated poor reproducibility. The exercise test methodology is obviously most important. We have used a standard free running exercise test lasting six minutes as recommended. ${ }^{9}$ This has been shown to be the most effective form of exercise to produce BHR. ${ }^{20}$ Other forms of exercise testing such as cold air enhanced bicycle ergometry have been shown to be an unsatisfactory tool in community studies. ${ }^{21}$

One limitation of exercise testing is ensuring that all the children produce submaximal effort. This can be done by measuring heart rate or oxygen consumption. ${ }^{9}$ Previous studies have confirmed that children will reach submaximal heart rates during a six minute test ${ }^{22}$ and indeed $90 \%$ of the children in the study by Haby et al reached maximum heart rates within one minute of starting exercise, showing that the majority of children were easily able to comply with the intensity requirement of the challenge. ${ }^{9}$ We found that $95 \%$ of the children assessed had heart rates over 170 beats per minute at the end of the test. We have attempted to ensure that all children were working as hard as they could throughout each test. Some of the children were stopped from running when it was considered that they were not running as hard as possible. Measuring the distance run is an indirect and imperfect method of assessing oxygen consumption ${ }^{23}$ and would make it possible to estimate whether the children had run at a suitable intensity $(30-45 \mathrm{ml} / \mathrm{kg} / \mathrm{min})$. We did not do this but Haby et al demonstrated that all but four of the children they tested reached the required intensity and those four actually reached heart rates of over 180 beats per minute and so were included in their analysis. ${ }^{9}$

We ensured that the absolute water content of the inspired air during the tests was always below $10 \mathrm{mg} \mathrm{H}_{2} \mathrm{O} / 1$ before testing, as an absolute water content above this level is considered to reduce the sensitivity of the test. ${ }^{24}$ The use of nose clips might theoretically increase the sensitivity of the test, although there are no definite data to confirm or refute this. ${ }^{25}$ In view of the potential problem of discomfort reducing compliance for repeated testing we decided not to use them in our study.

Measurement error may be another reason for poor reproducibility. We decided to measure the PEF using a Wright peak flow meter. It has been suggested that forced expiratory volume in one second $\left(\mathrm{FEV}_{1}\right)$ should be measured rather than PEF. ${ }^{9}$ This suggestion is based on a study examining over 200 children of 7 years that demonstrated a much lower reproducibility for PEF compared with $\mathrm{FEV}_{1}{ }^{26}$
However the PEF was measured using a pneumotachograph during a forced expiratory manoeuvre, which is the wrong manoeuvre for a PEF assessment, ${ }^{12} 27$ and pneumotachograph measurements are known to have a poorer reproducibility than Wright peak flow meter measurements. ${ }^{28}$ Other studies have shown Wright peak flow meter measurements to be more reproducible than $\mathrm{FEV}_{1}$ in children. ${ }^{29} 30$ In adults there are data to suggest the $\mathrm{FEV}_{1}$ is as reproducible as the Wright peak flow meter measurements. ${ }^{31}$ Mini-Wright peak flow meters have been shown to have a low reproducibility in community studies. ${ }^{32}$ Most community based exercise studies in children have used a Wright peak flow meter 2315 so we opted for this method.

To reduce observer and equipment bias, our study used the same two workers throughout the tests and used the same two peak flow meters, which were tested each time for accuracy. ${ }^{3}$ The worker measuring the PEF was blinded to each child's previous results and response. Each child used the same meter on each test. We have measured the PEF at five, 10 , and 15 minutes after exercise, which will identify a significant drop if present. ${ }^{20}$

As we have used the same methodology for each test and we have minimised the possibility of observer or equipment error, it is likely that the reason for the poor reproducibility of the test is the actual variability of the BHR within an individual over short periods of time. This is supported by the wide within-subject variability of responses to inhalation challenge test assessed regularly over short periods of time demonstrated in children with respiratory symptoms. ${ }^{33} 34$

There are a number of factors that can affect BHR. We attempted to ensure that every child had not exercised before each test as it is known that intensive exercise before a test may actually protect against BHR. ${ }^{35}$ This involved keeping children indoors during school breaks before the testing but we could not ensure that a child being tested in the morning did not exercise before coming to school. Each child was tested at the same time of day for each test thus controlling for any possible diurnal variation in airway tone. An URTI may affect the BHR response ${ }^{36}$ and we found a doubling of an association with a positive test and clinical evidence of an URTI. Excluding children with a current URTI makes little difference to the high coefficient of variation of a positive test and poor reproducibility at either cut off point for a fall index.

The variability of response within the population may be due to the variable numbers of children examined each time. It was not easy to control the absenteeism, injury, lack of cooperation, and children leaving and starting at the schools during the year of study. This would be the reality of testing regularly in schools, as has been suggested for screening. ${ }^{45}$ However, $83 \%$ of the children had seven tests and 45 were tested 10 times and there was no improvement in the coefficient of variation of test positivity in the 45 children whom were tested every time compared with the 143 
children tested using either a $15 \%$ or $20 \%$ fall index.

To decide on a cut off point for a 'normal' response to exercise we have examined a normative section of the cohort consisting of children who did not report current wheeze, asthma, or an atopic history. The mean plus 1.96 SD was used for the lower end of a 'normal' response and is a well described method for calculating cut off points. ${ }^{1314}$ Our normative population thus gave a cut off point at $20 \%$ which is much greater than other studies. Godfrey et al used $8 \cdot 2 \%,{ }^{14}$ Kattan et al calculated $10 \%,{ }^{13}$ and Haby et al used $13 \% .{ }^{9}$ The cut off point of $20 \%$ would comply with the original suggestions by Cropp, ${ }^{37}$ which also takes into consideration the reproducibility of the PEF measurements. This may suggest we have examined a more hyperresponsive population. Other more arbitrary cut off points have been used from $10 \%, 38$ $15 \%,{ }^{2}$ and $20 \%{ }^{39}$ We have also examined a cut off point of $15 \%$ for comparison with out studies.

It is of interest that using a $15 \%$ fall index nearly half of the children demonstrated a positive test on at least one occasion and only one child who had severe asthma gave a positive test each time we tested. If regular screening tests were set up to identify poorly controlled or undiagnosed asthma $\mathrm{a}^{45}$ eventually the screening would identify half of the population. As screening children by questionnaire has currently not been shown to reduce morbidity significantly, ${ }^{40}$ there is little justification for using exercise tests as a screen. Poor reproducibility and the current lack of evidence that screening reduces morbidity would make exercise testing a poor candidate for fulfilling the important criteria for an adequate screening test. ${ }^{10} \mathrm{We}$ have not examined the cost of identifying children by this method but if $50 \%$ of the children examined could potentially be identified as 'positive' on exercise testing this would put excessive strain on primary health services.

For use in prevalence studies over periods of time the exercise test also has to be interpreted with caution. Over one year we have been able to demonstrate between $6.5 \%$ and $23.3 \%$ frequency of a positive test using a $15 \%$ fall index or between $2.9 \%$ and $12.9 \%$ using a $20 \%$ fall index within the same population.

The high coefficient of variation for the test at either cut off point is of concern. Examining the response to exercise in a cohort of children and then examining another group of children a number of years later ${ }^{15}$ will thus be fraught with difficulties in interpretation.

In summary, under field conditions examining a heterogeneous group of children in the community over a year we have demonstrated the inadequacy of exercise testing as a screening test. Using exercise tests to support subjective questionnaire data with an objective measure of lung function in epidemiological studies of wheezy illness and asthma in children may well be a practical epidemiological tool $^{9}$ but with the poor reproducibility and large variation of individual and population response one has to interpret community based exercise data with caution.

We would like to thank the teacher, parents, and the children of the two primary schools involved in the study and $\mathrm{Mr}$ W Butcher for his assistance in the field.

This work was funded by the Sheffield Asthma Society.

1 Burr ML, Eldridge BA, Borysiewicz LK. Peak expiratory flow rates before and after exercise in schoolchildren. Arch Dis Child 1974; 49: 923-6.

2 Barry DMJ, Burr ML, Limb ES. Prevalence of asthma Wales: a comparative study. Thorax 1991; 46: 405-9.

3 Austin JB, Russell G, Adam MG, Mackintosh D, Kelsey S, Peck DF. Prevalence of asthma and wheeze in the highlands of Scotland. Arch Dis Child 1994; 71: 211-6.

4 Tsanakas JN, Milner RDG, Bannister OM, Boon AW. Free running asthma screening test. Arch Dis Child 1988; 63: 261-5.

5 Williams D, Bruton J, Wilson I. Screening a state middle school for asthma using the free running asthma screening test. Arch Dis Child 1993; 69: 667-9.

6 Silverman M, Anderson SD. Standardisation of exercise tests in asthmatic children. Arch Dis Child 1972; 47: 882-9.

7 Godfrey S. Exercise induced asthma - clinical, physiological and therapeutic implications. F Allergy Clin Immunol 1975; 56: $1-17$.

8 Green CP, Price JF. Prevention of exercise induced asthma by inhaled salmeterol xinafoate. Arch Dis Child 1992; 67 1014-7.

9 Haby MM, Anderson SD, Peat JK, Mellis CM, Toelle BG Woolcock AJ. An exercise challenge protocol for epidemiological studies of asthma in children: comparison with histamine challenge. Eur Resp f 1994; 7: 43-9.

10 Cochrane AL, Holland WW. Validation of screening procedures. Br Med Bull 1971; 27: 3-8.

11 Asher MI, Keil U, Anderson HR, et al. International study of asthma and allergies in childhood (ISAAC): rationale and methods. Eur Resp f 1995; 8: 483-91.

12 Polgar G, Promadhat V. Pulmonary function testing in children: techniques and standards. Philadelphia: Saunders, 1971 .

13 Kattan M, Keens TG, Mellis CM, Levison H. The response to exercise in normal and asthmatic children. $\mathcal{f}$ Pediatr to exercise in norma

14 Godfrey S, Springer C, Noviski N, Maayan CH, Avital A Exercise but not methacholine differentiates asthma from other chronic lung disease in children. Thorax 1991; 46: 488-92.

15 Burr ML, Butland BK, King S, Vaughan-Williams E Changes in asthma prevalence: two surveys 15 years apart. Arch Dis Child 1989; 64: 1452-6.

16 Clifford RD, Radford M, Howell JB, Holgate ST Prevalence of respiratory symptoms among 7 and 11 year old schoolchildren and association with asthma. Arch Dis Child 1989; 64: 1118-25.

17 Ninan TK, Russell G. Increasing prevalence of respiratory symptoms and atopy in Aberdeen schoolchildren: evisymptoms and atopy in Aberdeen schoolchildren: evi-
dence from two surveys 25 years apart. $B M \mathcal{F} 1992 ; 304$ : 873-5.

18 Powell CVE, Primhak RA. Asthma treatment, perceived respiratory disability, and morbidity. Arch Dis Child 1995 72: 209-13.

19 Peat JK, Salome CM, Brett GT, Bauman A, Woolcock AJ. The reliability of a respiratory questionnaire and effect on mode of administration on classification of asthma. Chest 1992; 102: 153-7.

20 Godfrey S, Silverman M, Anderson SD. Problems of interpreting exercise induced asthma. $\mathcal{f}$ Allergy Clin Immuno 1973; 52: 199-209.

21 Ninan TK, Russell G. Is exercise testing useful in a community based asthma survey? Thorax 1993; 48: 1218-21.

22 Tsanakas JN, Bannister OM, Boon AW, Milner RDG. The 'sport-tester': a device for monitoring the free running 'sport-tester': a device for monitoring
test. Arch Dis Child 1986; 61: 912-4.

23 Silverman M, Anderson SD. Metabolic cost of treadmill exercise in children. $\mathcal{F}$ Appl Physiol 1972; 33: 696-8.

24 Hahn A, Anderson SA, Morton AR, Black JL, Fitch KD. A reinterpretation of the effect of temperature and water content of the inspired air in exercise induced asthma. Chest 1992; 102: 153-7.

25 Sterk PJ, Fabbri LM, Quanjer PhH. Airway hyperresponsiveness: standardised challenge testing with pharmacological, physical and sensitizing stimuli in adults. Eur Resp f 1993; 6 (suppl 16): 53-83.

26 Strachan DP. Repeatability of ventilatory function measurements in a population survey of seven year old children. Thorax 1989; 44: 474-9.

27 Hsu KHK, Jenkins DE, Hsi BP, et al. Ventilatory functions in normal children and young adults. Mexican-American, white and black. II. Wright peak flow meter. $f$ Pediat 1979; 95: 192-6.

28 Chan N, Silverman $M$. Repeatability of ventilatory function measurements in a population survey of seven year old children. Thorax 1989; 44: 1059-60.

29 Cogswell J, Hull JM, Milner AD, Norman AP, Taylor B. Lung function in childhood. I. The forced expiratory volumes in healthy children using a spirometer and volumes in healthy children using a spirometer and reverse plethysmograp
Chest $1979 ; 69: 40-50$ 
30 Cotes JE, Dabbs JM, Hall AM, Heywood C, Laurence KM. Sitting height, free fat mass, and body fat as reference variables for lung function in healthy British school children; a comparison with stature. Ann Hum Biol 1979; 6: 307-14.

31 Dahlqvist MA, Eisen EA, Wegman DH, Kriebel D. Reproducibility of peak expiratory flow measurements. Reproducibility of peak exp
Occup Med 1993; 8: 295-302.

32 Frisher T, Meinert R, Urbanek R, Kuehr J. Variability of peak expiratory flow rate in children: short and long term reproducibility. Thorax 1995; 50: 35-9.

33 Josephs LK, Gregg I, Mullee MA, Holgate ST. Non-specific bronchial hyperreactivity and its relationship to the clinical expression of asthma. Am Rev Respir Dis 1989; 140: 350-7

34 Clough JB, Williams JD, Holgate ST. Profile of bronchial hyperresponsiveness in children with respiratory symptoms. Arch Dis Child 1992; 67: 574-9.

35 Schnall RP, Landau L. Protective effects of repeated short springs in exercise induced asthma. Thorax 1980; 35: 828-32.

36 Jenkins CR, Breslin ABX. Upper respiratory tract infections and airway reactivity in normal and asthmatic subjects. Am Rev Respir Dis 1984; 130: 879-83.

37 Cropp GJA. Relative sensitivity of different pulmonary function tests and the evaluation of exercise induced function tests and the evaluation of

38 Terblanche E, Stewart RI. The prevalence of exercise induced bronchoconstriction in Cape Town schoolchildren. S Afr Med 7 1990; 78: 744-7.

39 Foresi A, Mattoli S, Corbo GM, Polidori G, Ciappi G. Comparison of bronchial responses to ultrasonically nebulised distilled water, exercise, and methacholine in asthma. Chest 1986; 90: 822-6.

40 Hill R, Williams J, Britton J, Tattersfield A. Can morbidity associated with untreated asthma in primary schoolchildren be reduced? $B M \mathcal{F}$ 1991; 303: 1169-72.

\section{Preventing brain damage}

Think how wonderful it would be if we could prevent perinatal or neonatal hypoxia or ischaemia going on to produce cerebral palsy and other brain malfunctions. Well, there seems to be a real prospect that we might do just that.

Much of the damage after asphyxia is probably caused by excitatory neurotoxins (excitotoxins) acting through neuronal glutamate receptors. If these excitotoxins could be neutralised then nerve damage might be prevented.

The drug ibotenate is a glutamatergic agonist, acting as a competitive agonist of glutamate $N$-methyl-D-aspartate (NMDA) at postsynaptic receptors. When applied to cortical neurons during the later stages of neuronal migration it produces microgyria; after neuronal migration is complete the damage produced by ibotenate mimics that seen after perinatal and neonatal asphyxia with porencephalic cysts and other neocortical and white matter damage. One drug which might prevent excitotoxin induced damage is magnesium sulphate which prevents the lethal calcium influx into cells caused by the excitotoxins.

Workers in Brussels (Stéphane Marret and colleagues, Developmental Medicine and Child Neurology 1995; 37: 473-84) have studied the problem in mice. They injected ibotenate into the frontoparietal cortex of mice on the first or fifth postnatal day with or without a peritoneal injection of magnesium sulphate. Injection of ibotenate on the first day (when neuronal migration is not yet complete) produced microgyria and magnesium sulphate had no effect. Fifth day injection (when neuronal migration is complete) caused hypoxic-like lesions but magnesium sulphate was up to $80 \%$ protective for both neocortical and white matter lesions irrespective of whether the magnesium sulphate was given before or 10 minutes after the ibotenate. Presumably the issue of timing is crucial. How long is it before the damage becomes irreversible?

If these results can be transposed to the human they suggest that blocking neuroexcitatory toxins could be effective after about 26 weeks' gestation.

Clinical studies are already in progress and there are several other candidate protective drugs which will need evaluating. I do hope it works. We could be onto one of the biggest breakthroughs since Archimedes sat on a screw and jumped out of his bath. On the other hand, don't hold your breath; it could be a lemon. 